\title{
Considerations on the Evolutions and Particularities of the Human Development Index in European Countries
}

\author{
M Zaharia ${ }^{1}$ \\ ${ }^{1}$ Asociația pentru Democrație, Educație, Respect, România \\ marianzaharia53@gmail.com
}

\begin{abstract}
Starting from the fact that the index of human development is a mirror reflecting the integrated standard of living, education level and health of the population of a country, the paper presents and analyzes the evolution of the human development index in 46 European states during 1990-2017, as well and grouping and ranking them according to the values of their four components. The analyzes revealed that there are significant differences regarding the rank of some countries in the hierarchy of HDI values compared to its rank according to the individual values of the indicators that enter the HDI structure.
\end{abstract}

Keywords: HDI, GNI, Life expectancy of birth, Expected years of schooling

\section{Introduction}

The Human Development Index (HDI) was created in 1990 to highlight that people and their capabilities should be the key criteria for assessing a country's development (HDR, 2018). It highlights the level of development of a country, both from an economic point of view and the level of education and health of its population. Over time, the computational methodology as well as the HDI components have been subjected to a series of surveys. Thus, Cahill (2012) analyzed the robustness of HDI and pointed out that a multi-component alternative HDI would be more conclusive than the one used. Mishra (2009) proposes, instead of the linear mean to determine the indicator, to use the inverse of the Euclidean distance. Salas-Bourgoin (2014) proposes a Modified Human Development Index with three components: human capabilities (measured by mean years of schooling for adults and expected years of schooling for children), choices (employment ratio and Gross National Income per capita) and opportunities (life expectancy at birth and democracy index).

A synthesis of the evolution of HDI calculation methodologies is presented in Table 1 .

Currently HDI is determined from three dimensions (Figure 1): Long and Healthy Life, Knowledge and a decent standard of living. The method of calculating the HDI and the evolution of HDI in Romania is presented and analyzed by Lazăr \& Lazăr (2011) in the work Human development in Romania in the context of the new methodological approaches.

Also, Marginean (2012) performs a comparative analysis of HDI in Romania determined with both the new and the old methodology, pointing out that the place occupied by Romania in the ranking achieved with the new methodology is better than the previous one. 
Volume 1, Issue 1, 2019

ISSN: 2668-0416

Thoth Publishing House

Table 1. The indicators of Human Development Index

\begin{tabular}{|c|c|c|c|c|c|}
\hline Variables & UM & 1990 & $\begin{array}{l}\text { 1991- } \\
1994\end{array}$ & $\begin{array}{l}1995- \\
2009\end{array}$ & 2010 \\
\hline Life expectancy of birth & years & - & • & - & - \\
\hline Adult literacy rate & $\%$ & $\bullet$ & • & • & \\
\hline Gross enrolment ratio & $\%$ & & & $\bullet$ & \\
\hline Mean years of schooling & years & & - & & - \\
\hline Expected years of schooling & years & & & & $\bullet$ \\
\hline Gross Domestic Product (GDP) per capita & \$PPP & - & • & - & \\
\hline Gross National Income (GNI) per capita & \$PPP & & & & - \\
\hline
\end{tabular}

Source: Lazar, M., Lazar, C. (2011). Human development in Romania in the context of the new methodological approaches. Revista de Cercetare si Interventie Sociala, 33, p.143

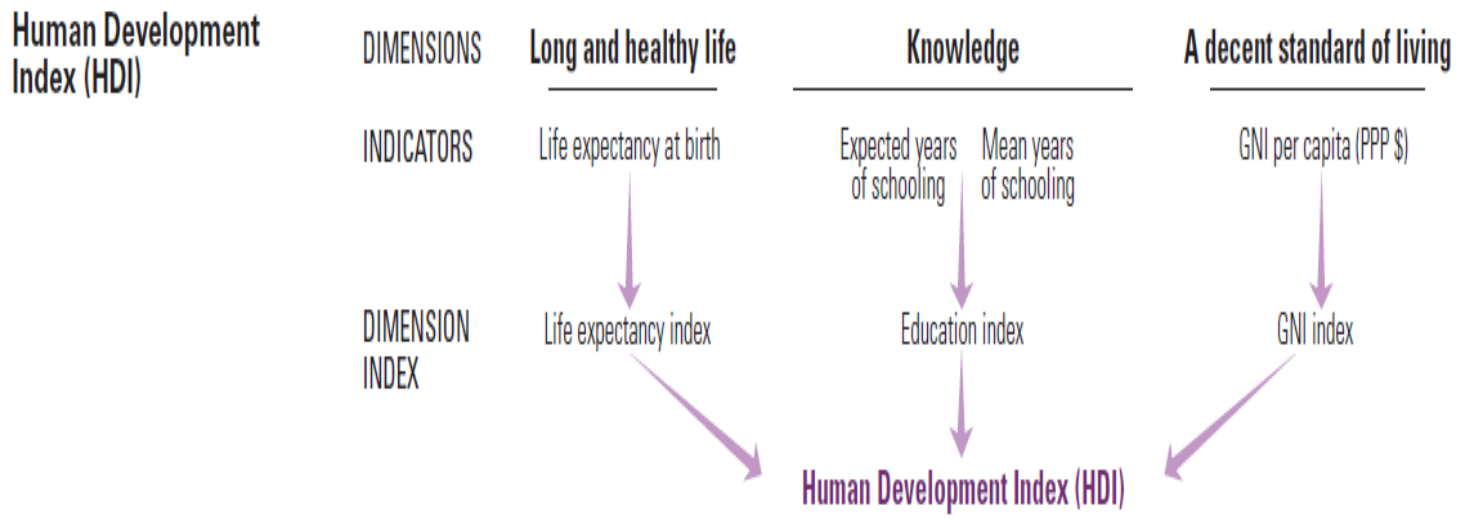

Figure 1. Human Development Index and its components Source: $\underline{\text { http://hdr.undp.org/en/composite/HDI }}$

Taking into account the relevance of HDI, a number of papers analyze it both independently and in correlation with other indicators. Thus, Opait (2015) analyzes the correlation between HDI, HPI (Happy Plant Index) and life expectancy, and Davies (2009) using the generalized method of moments analyzes the optimal government dimension on social welfare.

HDI offers a good opportunity for comparative analysis of the level of education and health welfare among different states, with the emphasis on the study Analyzing the composition of HDI in European countries (Ciupac-Ulici, 2015).

At the same time, HDI provides significant information on disparities and similarities in regional development (Moraru, 2017) and also household-based (Harttgen \& Klasen, 2012).

Starting from the aspects highlighted above, the present paper performs the analysis of HDI values in 46 European countries and has two objectives: the analysis of HDI evolution between 1990 and 2017 , as well as the analysis of the grouping of countries according to the four indicators defining HDI.

The paper, in its first part, analyzes the developments of HDI in Romania as well as in other 45 European states between 1990 and 2017, highlighting the changes in their hierarchies during the economic crisis, as well as in the pre- and post-crisis periods.

On the other hand, although HDI defines, at some point, the state of a nation in this respect, not infrequently countries with different levels of economic development relatively similar, differ either in terms of education level or in concerns the health of the population either or in both. Taking this into account, a cluster analysis of the structure of the 46 states is carried out in the second part of the paper, taking into account the values of the four indicators that are taken into account in determining HDI. 


\section{Research methodology}

Analyzes and researches on HDI and Its implication was used different methodologies. In addition to various statistical processing were used, among others, panel data regression (Ciupac-Ulici, 2015) or cluster analysis and F test (Çilingirtürk \& Koçak, 2018).

Taking into account the objectives of the analysis starting from HDI series of years and states (HDD, 1990-2017), the first part of the paper analyzed the HDI evolutions in Romania as well as in other 45 European states in the period analyzed on the basis of regression models, and the evolution of scores during the economic crisis, as well as in the pre- and post crisis.

To achieve the second goal, hierarchical cluster methodology was used. For this purpose the matrix $Y=\left\|y_{i j}\right\|_{i=\overline{1, n}, j=\overline{1, m}}$ was built, where $m=4$ (number of indicators) and $n=46$ (number of states included in the analysis).

Starting from this, the matrix of normalized values $Z=\left\|z_{i j}\right\|_{i=1, \overline{1, j}=\overline{1, m}}$ was generated, where:

$$
z_{i j}=\frac{y_{i j}-\bar{y}_{j}}{\sigma_{j}}, \quad \bar{y}_{j}=\frac{\sum_{i=1}^{n} y_{i j}}{n}, \quad \sigma_{j}=\sqrt{\frac{\sum_{i=1}^{n}\left(y_{i j}-\bar{y}_{j}\right)^{2}}{n-1}}
$$

For generate Proximity Matrix ( $W=\left\|w_{i j}\right\|_{i=\overline{1, n, j}=\overline{1, n}}$ ) was used Euclidian distance:

$W=\left\|w_{i j}\right\|_{i=1, n, j=1, n}, \quad w_{i j}=\sqrt{\sum_{i=1}^{n}\left(z_{i k}-z_{i j}\right)^{2}}, j=\overline{1, m}, k=\overline{1, m} j \neq i, k \neq i, w_{i i}=0$

Average linkage between groups method was used to generate clusters.

For the validation of the results Test of Homogeneity of Variances based on Levene Statistic and ANOVA methodology was used, and if the null hypothesis of the Test of Homogeneity of Variances is rejected the Robust Tests of Equality of Means (Welch and Brown-Forsythe) was used.

To test the statistical significance of the results was used Confidence level 95\% (significance threshold $\alpha=0.05$ ).

Data processing was performed using SPSS.

\section{Results and discussions}

\section{Significant increases in HDI}

General trend of HDI during the period under review was upward one. If in 1990 the highest HDI was recorded in Norway (0.850) and the smallest in Turkey (0.579), the difference being 27.1 percentage points, in 2017 (Figure 2) the difference between the maximum value also recorded in Norway 0.953) and the lowest value recorded in Moldova (0.700) is reduced to 25.3 percentage points. These evolution highlight a slightly convergent process. 


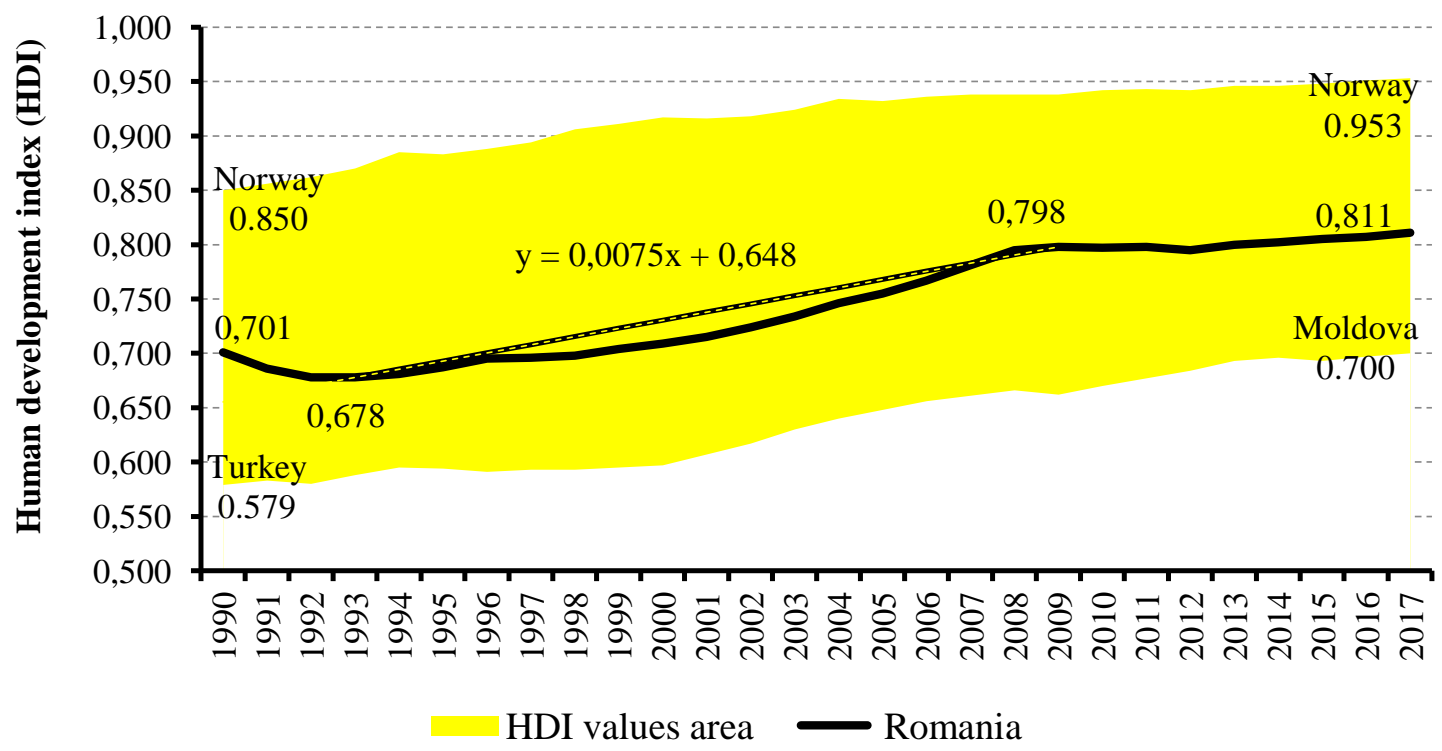

Figure 2. Evolution of HDI in Romania and HDI values area in European countries between 1990 and 2017

However, periods of divergent developments have been recorded over the period under review. Thus, due to the downward evolution of HDI in the Republic of Moldova between 1990 and 2000, from 0.651 to 0.597 , the difference between the highest and the lowest HDI values increases to 32 percentage points. It is noteworthy that this evolution was determined by a single state from the 44 states for which data were available for 2000 (For Montenegro data are available from 2003 and for Macedonia only for 2017).

For Romania, HDI has evolved with alternatives of increasing and decreasing. Thus, from a value of 0.701 registered in 1990, HDI decreases to 0.678 in 1993 . This is followed by a growth period until 2009 when it reaches 0.798 , the average annual growth being 0.75 percentage points.

The economic crisis also induces a decline in HD in Romania by 2012, when it reaches 0.795 . In the last part of the analyzed period, the growth process rebounds to reach 0.811 in 2017. Although compared to 1990, HDI was higher by 11.0 percentage points in HDI in 2017, in HDI hierarchy Romania ranks 32th out of 38 states registered in 1990, ranked 35th out of 46 states in 2017.

To highlight changes in HDI hierarchies, five value ranges each representing $20 \%$ of the difference between the maximum and minimum HDIs of that year were generated. In 1990, out of the 38 countries for which HDI was available, 8 countries (Hungary, Switzerland, the Netherlands, Sweden, Belgium, Iceland, Germany and Denmark) were included in the first range, with two states included in the last interval: Armenia and Turkey. In the same year, Romania was in the third value range, ranking 13th out of the 17 states included in this range.

The HDI developments recorded in the analyzed states highlight a strong concentration trend in the first two value ranges (Figure 3). So. If in 1990 in the first two value intervals (with HDI values higher than 0.748 ) were included $47.37 \%$ of the states included in the analysis at that time, in 2017 the share of states included in these intervals (with HDI values higher than 0.0 .852 ) reaches 58.69\%. 


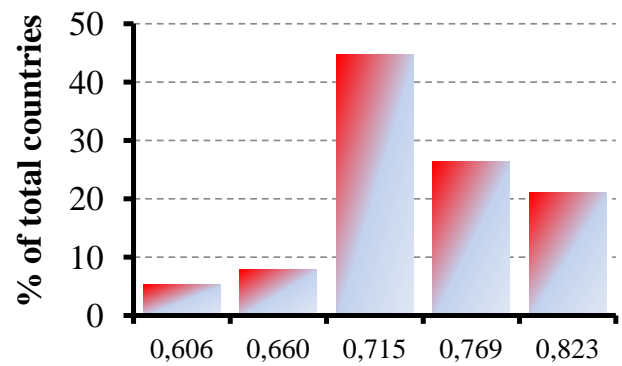

The averages of value ranges 1990

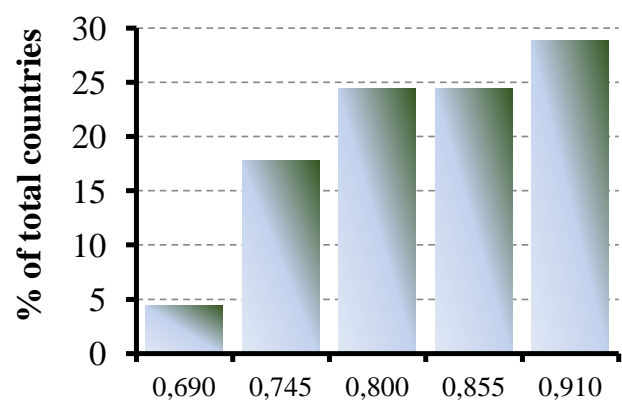
2009

The averages of value ranges

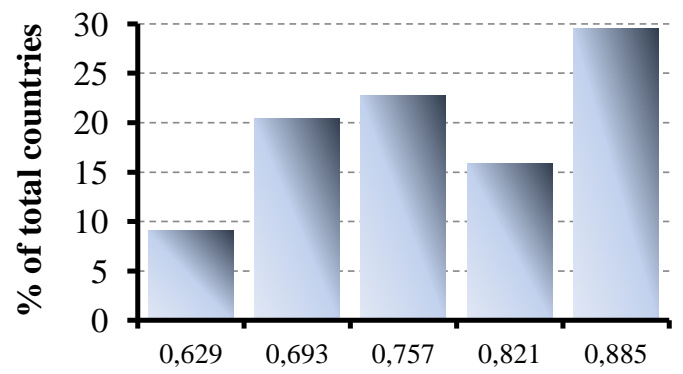

The averages of value ranges

2000

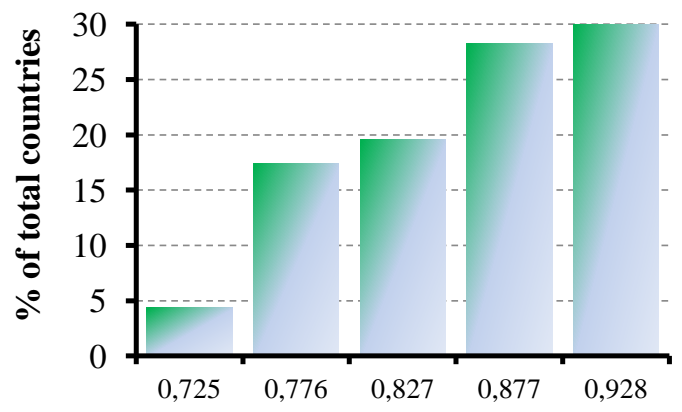

2017

The averages of value ranges

Figure 3. Structural evolutions on HDI value range

a. Simillatities and disparities in $\mathbf{2 0 1 7}$

Considering that the HDI is a synthesis indicator whose value is determined by linear transformations based on four basic indicators (Life expectancy of birth, Expected years of schooling, Mean years of schooling and Gross National Income per capita), its final value may hide contradictory values of the base indicators so that two states with the same HDI value may differ significantly from baseline indicators. Starting from this consideration, the initial analysis of HDI in the European countries was extended by an analysis of the grouping of these states, taking into account only the values of the four basic indicators registered in 2017 at the level of 46 European states. The coding and measurement units of the variables included in the analysis are shown in Table 2.

Table 2. Codlings and measurement units of the variables included in the analysis

\begin{tabular}{clc}
\hline \hline CODE & \multicolumn{1}{c}{ VARIABLES } & UNIT \\
\hline LEB & Life expectancy of birth & years \\
EYS & Expected years of schooling & years \\
MYS & Mean years of schooling & years \\
GNI & Gross National Income per capita & $\$$ \\
\hline \hline
\end{tabular}

Following the analyzes performed in the classification process and taking into account the dendogram shown in Figure 3, a six-cluster structure was chosen. 


Latvia
Lithuania
Slovakia
Estonia
Poland
Czechia
Bulgaria
Hungary
Croatia
Montenegro
Romania
Serbia
Belarus
Georgia
Russian Federation
Ukraine
Azerbaijan
Moldova
Armenia
Albania
Bosnia and Herzegovina
Macedonia
Turkey
Germany
Switzerland
Denmark
Ireland
Iceland
Belgium
Netherlands
Sweden
Finland
United Kingdom
Slovenia
Norway
France
Malta
Austria
Cyprus
Italy
Spain
Greece
Portugal
Andorra
Luxembourg
Liechtenstein

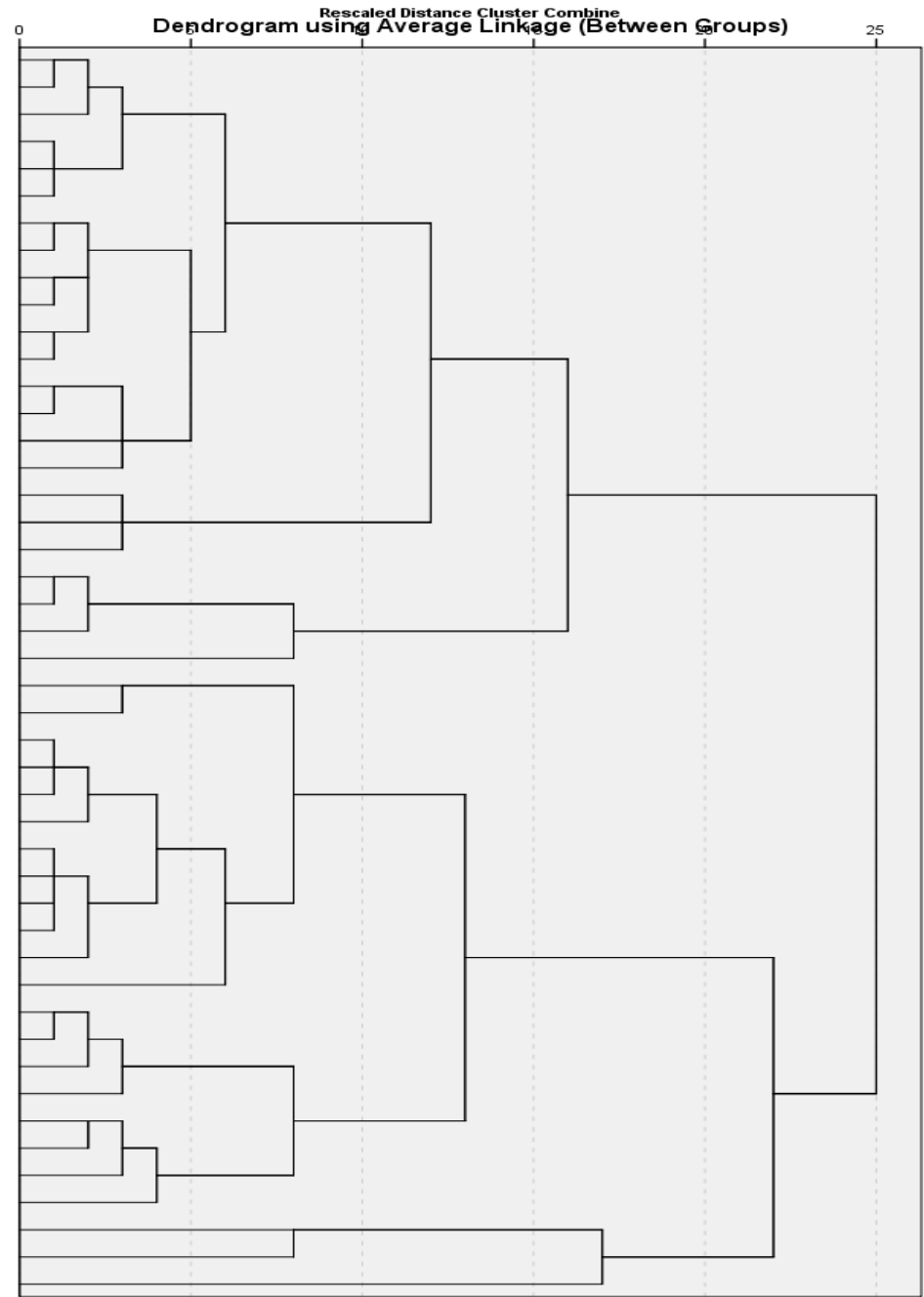

Figure 3. Dendogram

The structure of the clusters is presented in Table 3. In brackets, the places occupied in the hierarchy of HDI values in 2017 are shown. For example, Norway, with the highest HDI value recorded in 2017, is included in cluster 4 taking into account the particular values of the four indicators.

Table 3. Structure of clusters generated by the normalized values of LEB, EYS, MYS and GNI recorded in 2017 in the 46 European countries

Cluster COUNTRIES AND HDI RANKS IN 2017

1 Albania (39), Bosnia and Herzegovina (41), Macedonia (43), Turkey (37)

Armenia (44) Azerbaijan (42), Belarus (36), Bulgaria (34), Croatia (31),

2 Czech Republic (18), Estonia (21), Georgia (40), Hungary (30), Latvia (28),

Lithuania (26), Moldova (46), Montenegro (33), Poland (24), Romania (35), Russian

Federation (32), Serbia (38), Slovakia (27). Ukraine (45)

3 Austria (13), Cyprus (23), France (15), Greece (22), Italy (19), Malta (20), Portugal (29), Spain (17) 


\begin{tabular}{cl}
\hline \hline Cluster & \multicolumn{1}{c}{ COUNTRIES AND HDI RANKS IN 2017 } \\
\hline 4 & $\begin{array}{l}\text { Belgium (11), Denmark (8), Finland (10), Germany (4), Iceland (5), Ireland (3), } \\
\text { Netherlands (7), Norway (1), Slovenia (16), Sweden (6), Switzerland (2), United Kingdom } \\
(9)\end{array}$ \\
\hline 5 & Andorra (25), Luxemburg (14) \\
\hline 6 & Liechtenstein (12) \\
\hline \hline
\end{tabular}

To test the statistical significance of variables belonging to the cluster analysis, initially it tried using ANOVA methodology and Fisher test .

However, with the result of the application of the Test of Homogeneity of Variances (Table 4), it was found that for the LEB variable, the null hypothesis (the homogeneity hypothesis) was rejected, (Sig. $=0.004<\alpha=0.05)$ the ANOVA methodology could not be applied.

Table 4. Test of Homogeneity of Variances

\begin{tabular}{ccccc}
\hline \hline Variable & Levene Statistic & df1 & df2 & Sig. \\
\hline LEB & 4.649 & 4 & 40 & 0.004 \\
EYS & 0.558 & 4 & 40 & 0.694 \\
MYS & 1.866 & 4 & 40 & 0.135 \\
GNI & 0.560 & 4 & 40 & 0.693 \\
\hline
\end{tabular}

Under these conditions, Robust Tests of Equality of Means were applied, whose null hypothesis is: the average values do not differ significantly from zero (their values are not statistically significant). Following the test, both the Welch statistic and the Brown-Forsythe statistic (Table 5) lead to the rejection of the null hypothesis. Consequently, the mean values of the variables included in the clusters are statistically significant.

Table 5 Robust Tests of Equality of Means

\begin{tabular}{|ll|r|r|r|r|}
\hline & \multicolumn{1}{|c|}{ Statistic $^{\mathrm{a}}$} & df1 & df2 & \multicolumn{1}{c|}{ Sig. } \\
\hline LEB & Welch & 45.011 & 4 & 11.269 & 0.000 \\
& Brown-Forsythe & 84.128 & 4 & 26.727 & 0.000 \\
\hline EYS & Welch & 25.394 & 4 & 8.661 & 0.000 \\
& Brown-Forsythe & 27.440 & 4 & 32.589 & 0.000 \\
\hline MYS & Welch & 10.603 & 4 & 5.557 & 0.009 \\
& Brown-Forsythe & 10.080 & 4 & 4.755 & 0.015 \\
\hline GNI & Welch & 19.143 & 4 & 5.826 & 0.002 \\
& Brown-Forsythe & 24.760 & 4 & 4.626 & 0.002 \\
\hline
\end{tabular}

a. Asymptotically F distributed.

The main characteristics of the clusters are presented in Table 6. The cluster numbering was performed in the increasing order of the average Gross National Income per capita.

Cluster One includes four states and is characterized by the lowest GNI $(\$ 15,228)$. Although, as noted above, the average GNI in this cluster is statistically significant, the coefficient of variation (V = $42.0 \%$ ) warns that it does not give a quite relevant to the standard of living in this cluster. This is due to the fact that in Turkey, the GNI of 2017 is double the GNI values recorded in each of the other three states. 
With the exception of the GNI for the other three indicators, variance coefficient values are less than $10 \%$, meaning that the average values of LEB, EYS and MYS provide relevant images to countries in this cluster. Of these three indicators, MYS also records the smallest value (9.3 years) compared to the other clusters.

Although from the point of view of GNI and MYS cluster 1 is the most unfavorable, with respect to the average values of LEB and EYS, they are in the penultimate place before cluster 2 and cluster 5. It should also be underlined that that Armenia, Ukraine and the Republic of Moldova, which are in the last three places in terms of HDI values, are not in this cluster, but in cluster 2 with a superior standard of living.

The cluster 2 includes nineteen countries, and in terms of the average values registered at its level, are characterized by levels of GNI, EYS and MYS higher, both in relation to the cluster 1 (with $29.75 \%$ of the HNI, $27.96 \%$ to MYS and with $3.47 \%$ for EYS), and compared with other clusters.

Note that Knowledge dimension, which includes the Expected Years of Schooling (EYS) and Mean Years of Schooling (MYS), shows higher values in Cluster 2 than clusters with higher living standards. Thus the MYS value recorded in cluster 2 is $9.17 \%$ higher than in cluster 3 and $6.25 \%$ higher than in cluster 5. Also, the EYS value recorded in cluster 2 is $7.98 \%$ higher than in cluster 5 and $1.36 \%$ higher than in cluster 6.

On the other hand, however, in cluster 2 the lowest value of Life expectancy of birth is recorded. This is less about 2 years from cluster 1, over 5 years less than cluster 6 and nearly 7 years less than clusters 3,4 and 5 .

Taking into account the classification criteria used, Romania, ranked 35 in the HDI hierarchy and in 2017, is in cluster 2 as well. Compared to the average values of the four indicators at the cluster level, Romania recorded a significantly higher value on GNI $(\$ 22,6746), \$ 2887$ more than the GNI average, and about 1 year higher than the LEB average. On the other hand, in terms of Knowledge dimension, the values recorded in Romania are lower than the cluster average, i.e. only 14.3 years for EYS and 11 years for MYS.

Table 6. Characteristics of the clusters generated by the LEB, EYS, MYS and GNI variables recorded in 2017 in 46 European states

\begin{tabular}{|c|c|c|c|c|c|c|c|c|c|c|c|c|}
\hline \multirow[b]{2}{*}{$\begin{array}{l}\overline{\bar{U}} \\
\underline{0} \\
\bar{\Xi}\end{array}$} & \multicolumn{3}{|c|}{ LEB } & \multicolumn{3}{|c|}{ EYS } & \multicolumn{3}{|c|}{ MYS } & \multicolumn{3}{|c|}{ GNI } \\
\hline & $\begin{array}{l}\text { Mean } \\
\text { (year) }\end{array}$ & $\begin{array}{l}\text { Std. } \\
\text { Dev. }\end{array}$ & $\begin{array}{c}\mathrm{V} \\
(\%)\end{array}$ & $\begin{array}{l}\text { Mean } \\
\text { (year) }\end{array}$ & $\begin{array}{l}\text { Std. } \\
\text { Dev. }\end{array}$ & $\begin{array}{c}\mathrm{V} \\
(\%)\end{array}$ & $\begin{array}{l}\text { Mean } \\
\text { (year) }\end{array}$ & $\begin{array}{l}\text { Std. } \\
\text { Dev. }\end{array}$ & $\begin{array}{c}\mathrm{V} \\
(\%)\end{array}$ & $\begin{array}{c}\text { Mean } \\
(\$)\end{array}$ & $\begin{array}{l}\text { Std. } \\
\text { Dev. }\end{array}$ & $\begin{array}{c}\mathrm{V} \\
(\%)\end{array}$ \\
\hline 1 & 76.88 & 1.21 & 1.6 & 14.4 & 0.83 & 5.7 & 9.3 & 0.90 & 9.6 & 15228 & 6393 & 42.0 \\
\hline 2 & 75.07 & 2.32 & 3.1 & 14.9 & 1.30 & 8.7 & 11.9 & 0.70 & 5.9 & 19759 & 7993 & 40.5 \\
\hline 3 & 81.94 & 1.01 & 1.2 & 16.4 & 0.97 & 6.0 & 10.9 & 1.07 & 9.8 & 34019 & 6523 & 19.2 \\
\hline 4 & 81.88 & 0.79 & 1.0 & 18.1 & 1.14 & 6.3 & 12.6 & 0.61 & 4.8 & 47316 & 9506 & 20.1 \\
\hline 5 & 81.85 & 0.21 & 0.3 & 13.8 & 0.35 & 2.6 & 11.2 & 1.34 & 12.0 & 56295 & 12333 & 21.9 \\
\hline 6 & 80.41 & - & - & 14.7 & - & - & 12.5 & - & - & 97336 & - & - \\
\hline
\end{tabular}

Cluster 3 includes eight states. The difference between the average level of GNI recorded in this group and the values recorded in the first two clusters is significantly higher (2.23 times higher than cluster 1 and 1.72 higher than cluster 2). Also, a feature of the average value of GNI is that it provides a relevant image of the standard of living in the eight states, as evidenced by the value of the coefficient of variation $(\mathrm{V}=19.2 \%)$.

Another feature of this cluster is that it has the highest LEB value with 9.15\% higher than Cluster 2 (6.87 years), with $6.59 \%$ than Cluster 1 (5.06 years), with $1.90 \%$ then Cluster 6 (1.53\% years), and less than $1 \%$ compared to clusters 4 and 5 . 
Among the countries included in this cluster, the highest LEB value in 2017 was recorded in Spain (83.3 years) and the lowest in Malta (81.0 years).

As for Knowledge size, cluster 3 is one of contrasts. While in terms of EYS, with the exception of cluster 4, cluster 3 recorded the highest values (between 18.84\% higher than in cluster 5 and $10.10 \%$ higher than cluster 2), from the point of view of MYS recorded values are lower than in the other clusters. Exception makes the cluster one.

Cluster 4 includes 12 countries with an average cluster GDP of $\$ 47,316$ and characterized by a good representatively $(\mathrm{V}=21.1 \%)$. A very important feature of this cluster is that it includes all the top 11 countries in the HDI hierarchy, as well as Slovenia (16th place).

Another important feature of cluster 4 is that the Knowledge dimension records the dominant values for both EYS and MYS. Thus, with regard to EYS, the recorded value is higher than in the other five clusters with percentages between $10.37 \%$ (cluster 3) and $31.16 \%$ (cluster 5), and at MYS the recorded value is higher than in the other five clusters, with percentages between $0.8 \%$ (cluster 6 ) and $35.48 \%$ (cluster 1 ).

Cluster 5 includes two countries (Andorra and Luxembourg), and Liechtenstein forms the cluster 6 itself. These two clusters are characterized by the fact that they include particular cases and, in a way, highlight the imperfections of the current calculation of HDI.

The main feature of cluster 5 is that in the two countries the lowest EYS values are recorded compared to any of the other clusters. In Andorra EYS is 13.5 years old, and in Luxembourg 14.0 years. For example, Luxembourg with a GNI of \$ 65016 is ranked 3 after Liechtenstein and Norway, but has one of the lowest levels of Knowledge, ranking 41th out of 46 states at EYS, and 23rd at MYS.

A similar situation is also observed in Liechtenstein, which, although it has a GNI of $\$ 97,336$, 1.43 times higher than in Norway (ranked second in this respect) and 17.53 times higher than in the Republic of Moldova (ranked on the last place), has a relatively low level of Knowledge being ranked 36th out of a total of 46 states at EYS and 11th at MYS.

\section{Conclusions}

The Human Development Index is a synthetic indicator that characterizes, with good relevance, the level of development of a country, from economic, knowledge and health points of view. The evolution of this indicator between 1990 and 2017 highlights both a growth process (development) and a convergent process that contributes to reducing the gaps between European countries.

However, the convergence process is one that manifests itself with different intensities, being more intense in the countries in the first part of the ranking, and less intense in its second part. This leads to an increase in the differences between the developed and the least developed countries, as evidenced by the way they are grouped in clusters in 2017.

Finally, but not least, it has resulted as HDI computation by linearly combining the values of the four indicators taken into account in the current methodology hides certain discrepancies, in the sense that countries with similar levels of development may differ significantly from point of view of knowledge dimension, which leads to significant differences in their ranking from the point of view of HDI. For example, Luxembourg with a GNI relatively close to GNI registered in Norway is ranked 14th, while Norway is ranked first.

\section{References}

[1] Cahill, M. (2002), How Robust is the Human Development Index?, No 0203, Working Papers, College of the Holy Cross, Department of Economics, https://EconPapers.repec.org/ RePEc:hcx:wpaper:0203.

[2] Ciupac-Ulici, M. (2015), Analyzing the Composition of HDI in European Countries, Studies in Business and Economics, 10, issue 3, p. 119-127.

[3] Davies, A. (2009 Human development and the optimal size of government, Journal of Behavioral 
and Experimental Economics (formerly The Journal of Socio-Economics), 38, issue 2, p. 326-330

[4] Harttgen, Kenneth and Klasen, Stephan, (2012), A Household-Based Human Development Index, World Development, 40, issue 5, p. 878-899.

[5] HDD (1990-2017) United Nations Development Programme. Human Development Reports. Human Development Data (1990-2017) http://hdr.undp.org/en/data\# Accessed August 10, 2018.

[6] HDR (2018). Human Development Report. http://hdr.undp.org/en/content/human-developmentindex-hdi. Accessed September 12, 2018.

[7] Mărginean, I. (2012), Performanţa României în domeniul dezvoltării umane, Calitatea vieţii, XXIII, nr. 4,p. 277-298.

[8] Mishra, S., Nathan, H. S. K. and Reddy, S. (2009), An Alternative Approach to Measure HDI, Working Papers, Social Sciences, https://EconPapers.repec.org/RePEc:ess:wpaper:id:2069

[9] Moraru G. O. (2017) Human Development Index in the Context of Regional Disparities. The case of Romania, Annals - Economy Series, 2 Special, issue , p. 162-168.

[10] Opait, G. (2015) The Intensity of The Correlation Between The Human Development Index, Respectively The Happy Planet Index and The Life Expectancy, in Romania, Risk in Contemporary Economy, issue , p. 90-99.

[11] Salas-Bourgoin, M.A. (2014), A proposal for a modified Human Development Index, Cepal Review, no. 112, pp. 29-44 